\title{
Invasion of human respiratory epithelial cells by Bordetella pertussis: Possible role for a filamentous hemagglutinin Arg-Gly-Asp sequence and $\alpha 5 \beta 1$ integrin
}

\author{
Yoshio Ishibashi ${ }^{a *}$, David A. Relman ${ }^{b} \&$ Akemi Nishikawa ${ }^{a}$ \\ ${ }^{a}$ Department of Immunobiology, Meiji Pharmaceutical University, Noshio, Kiyose, Tokyo 204-8588, \\ Japan, ${ }^{b}$ Departments of Microbiology and Immunology, and Medicine, Stanford University School of \\ Medicine, Stanford, CA 94305, and Veterans Affairs Palo Alto Health Care System, Palo Alto, \\ CA 94304, U.S.A.
}

(Received October 27, 2000; accepted in revised form January 10, 2001)

Bordetella pertussis, the agent of whooping cough, is capable of invading human respiratory epithelial cells. In this study, we investigated the mechanisms by which $B$. pertussis invades the human lung epithelial cell line A549 and normal human bronchial epithelial (NHBE) cells. In vitro adhesion and invasion assays using both cell types with a virulent $B$. pertussis strain and its isogenic mutants revealed profound defects in a mutant deficient in filamentous hemagglutinin (FHA) expression. In addition, a mutant in which an FHA Arg-Gly-Asp (RGD) site had been changed to Arg-Ala-Asp had significantly diminished invasiveness, although its adhesiveness was comparable to that of the parental strain. Furthermore, a synthetic RGD-containing hexapeptide inhibited invasion of both cell types by the virulent strain. These results demonstrate that an RGD sequence of FHA is involved in B. pertussis invasion of epithelial cells in vitro. Monoclonal antibodies directed against human $\alpha 5 \beta 1$ integrin, but not other integrins, blocked invasion, indicating that this integrin is involved in B. pertussis invasion. Taken together, these findings suggest that $B$. pertussis FHA may promote invasion of human respiratory epithelial cells through the interaction of its RGD sequence with host cell $\alpha 5 \beta 1$ integrin.

(C) 2001 Academic Press

Key words: Bordetella pertussis, integrin, human epithelial cell, invasion.

\section{Introduction}

The causative agent of whooping cough, Bordetella pertussis, is a Gram-negative coccobacillus

* Author for correspondence. E-mail: yishibas@my-pharm. ac.jp

0882-4010/01/050279+10\$35.00/0 which attaches to ciliated epithelial cells in the respiratory tract and causes disease through the action of several bacterial toxins [1]. Various $B$. pertussis virulence factors have been identified and characterized; some virulence factors including filamentous hemagglutinin (FHA), fimbriae (Fim), pertactin (Prn) and pertussis toxin 
(PT) mediate adherence to mammalian cells; others such as adenylate cyclase toxin (ACT), tracheal cytotoxin (TCT), dermonecrotic toxin (DNT) and PT exert toxic effects on a variety of host cells $[2,3]$. The expression of most of these virulence factors is coordinately regulated by the two-component response regulatory system BvgAS that is encoded by the bvg locus, that responds to environmental factors such as $\mathrm{MgSO}_{4}$, nicotinic acid and temperature [4-6]. Although B. pertussis has long been considered to be an exclusively extracellular pathogen, recent findings have shown that $B$. pertussis can invade and survive in monocytes/macrophages and several types of epithelial cells [7-11]. The ability of $B$. pertussis to survive within host cells could provide mechanisms for escape from host immune defenses, and/or the establishment of a quiescent carrier state in an intracellular environment. However, the precise mechanisms by which $B$. pertussis invade human respiratory epithelial cells remains to be elucidated. Previous studies of intracellular invasion by some bacterial pathogens have revealed that entry of bacteria into non-phagocytic cells is a multifactorial process with participation of both bacterial factors and host cell surface components [12-15]. In the case of Yersinia, the outer membrane protein invasin binds to $\beta 1$ integrin receptors, leading to bacterial entry [12]. Listeria monocytogenes also relies on ligand-receptor, protein-protein interactions to enter the human enterocyte-like epithelial cell line Caco-2 and some other epithelial cells; i.e. host E-cadherin serves as a receptor for the bacterial protein internalin (InlA) [13, 14]. For Shigella flexneri, the interaction of Ipa proteins with $\alpha 5 \beta 1$ integrin promotes entry of the bacteria into epithelial cells [15]. Therefore, it can be postulated that a bacterial factor and its complementary receptor on the host cell surface probably have considerable bearing on the success of bacterial invasion.

Invasion of epithelial cells by $B$. pertussis appears to be a bvg-dependent process, as $b v g$ mutants were much less invasive $[11,16]$. Recently, Bassinet et al. [7] have shown that $B$. pertussis FHA promotes invasion of human tracheal epithelial cells, whereas ACT and Prn impair this process. FHA is a $220 \mathrm{kDa}$ protein that is both secreted and cell-associated [17]. FHA contains at least four distinct binding domains: (i) the Arg-Gly-Asp (RGD) sequence for leukocyte response integrin/integrin- associated protein complex which mediates binding to monocytes through the upregulation of the complement receptor type 3 (CR3) [18, 19]; (ii) a CR3 recognition domain [18]; (iii) a carbohydrate recognition domain (CRD) which mediates attachment to ciliated respiratory epithelial cells as well as to macrophages [20]; and (iv) a binding domain for heparin and other sulfated carbohydrates which can mediate adherence to nonciliated epithelial cell lines in vitro [21]. None of these FHA domains, or host receptors, have been implicated in invasion of respiratory epithelial cells to date. In this study, using the cultured human lung epithelial cell line A549 and primary normal human bronchial epithelial cells, we investigated the mechanism by which $B$. pertussis invades respiratory epithelial cells. Our results suggest that B. pertussis FHA may promote the invasion of human respiratory epithelial cells through the interaction of its RGD sequence with host cell $\alpha 5 \beta 1$ integrin.

\section{Results}

\section{Kinetics of the adherence to, and invasion of, A549 epithelial cells by $B$. pertussis BP536}

In order to define the characteristics of our assays, we examined a time course of adherence to, and invasion of, A549 cells by B. pertussis. A549 cells were infected with B. pertussis BP536 at an moi of 100 , and the numbers of viable cell-associated and intracellular bacteria were determined after various time intervals (Fig. 1). The adherence to and invasion of A549 cells by BP536 were complete after 1 and $2 \mathrm{~h}$ incubation, respectively. An incubation as long as $4 \mathrm{~h}$ showed no significant increase in the numbers of cell-associated and intracellular bacteria. In this assay, after $2 \mathrm{~h} 9.7 \pm 2.3 \%$ of the total number of A549-associated bacteria were resistant to gentamicin, and hence, were defined as intracellular.

To confirm the intracellular presence of bacteria, A549 cell monolayers were infected with B. pertussis $\mathrm{BP} 536$ at an moi of 100 at $37^{\circ} \mathrm{C}$ for $2 \mathrm{~h}$ and were examined by TEM (Fig. 2). TEM showed that most intracellular bacteria were entrapped in tight endocytic vacuoles [Fig. 2(a) and (b)]. Similar results were obtained with NHBE cells (data not shown). 

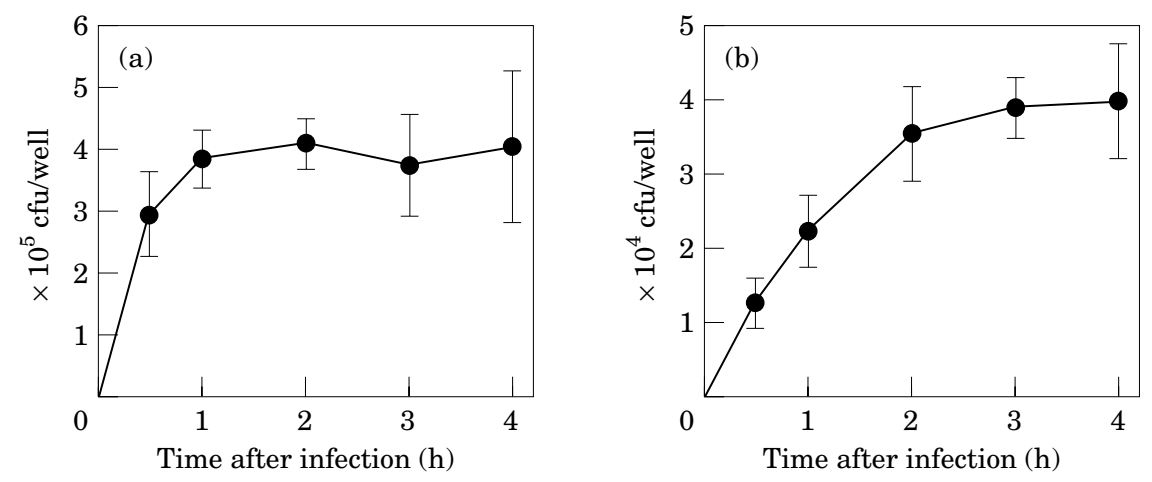

Figure 1. Time course of adherence to and invasion of A549 cells by B. pertussis BP536. A549 cell monolayers $\left(1 \times 10^{5}\right.$ cells / well) were infected with $10^{7} \mathrm{cfu} B$. pertussis BP536 for $30 \mathrm{~min}, 1,2,3$ and $4 \mathrm{~h}$ at $37^{\circ} \mathrm{C}$. The infected cells were treated or not treated with gentamicin for $2 \mathrm{~h}$ at $37^{\circ} \mathrm{C}$. The cells were washed and lysed. Appropriate dilutions of the cell lysates were plated onto BG agar plates. The numbers of viable bacteria from the cells untreated with gentamicin were counted as the total number of cell-associated bacteria (a). The gentamicinresistant bacteria were defined as intracellular bacteria (b). The values represent the means $\pm S E$ of four experiments.
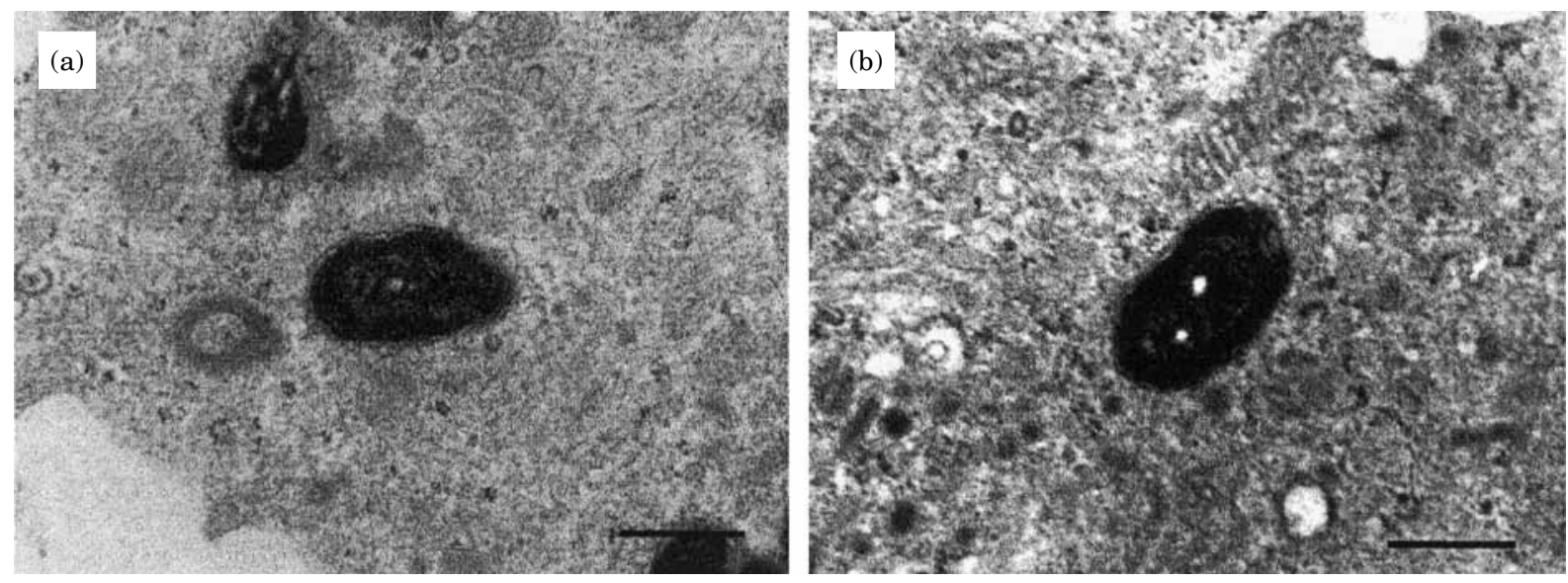

Figure 2. Transmission electron micrographs demonstrating B. pertussis invasion of A549 cells. A549 cell monolayers $\left(1 \times 10^{5}\right.$ cells/well) were infected with B. pertussis BP536 at an moi of 100 at $37^{\circ} \mathrm{C}$ for $2 \mathrm{~h}$. In (a) and (b), intracellular bacteria are entrapped in tight endocytic vacuoles. Bar $=0.5 \mu \mathrm{m}$.

\section{RGD sequence of FHA is required for maximal invasion of human respiratory epithelial cells by $B$. pertussis}

In order to assess the role of bacterial factors in the invasion of epithelial cells, A549 cells were infected with various isogenic mutant strains of B. pertussis. After $2 \mathrm{~h}$ incubation at $37^{\circ} \mathrm{C}$, bacterial adherence and invasion were assessed (Fig. 3). The ability of B. pertussis BP536 to adhere and invade A549 cells was similar to that of wild type strain Tohama I. B. pertussis BP537, the avirulent (Bvg-) derivative of strain BP536, did not adhere to, or invade A549 cells, indicating a role for $b v g$-regulated virulence factors in the interaction between $B$. pertussis and respiratory epithelial cells. Mutant strain BP200, deficient in FHA, was reduced in its ability to adhere to $(27.6 \%$ of the parental strain BP536; $P<0.05)$ and invade $(9.1 \%$ of BP536; $P<0.01)$ A549 cells. Strain BP1098, an isogenic derivative of BP536 that contains a site-directed chromosomal mutation resulting in a Gly $\rightarrow$ Ala substitution at the RGD site of FHA, showed a significantly reduced invasiveness $(43.2 \%$ of BP536; $P<0.05)$, although its adhesiveness was similar to that of the parental strain BP536. In contrast, the adhesive and invasive properties of strain BP-TOX6, deficient in PT, or strain BPA2-6, deficient in AC activity, were indistinguishable from those of 

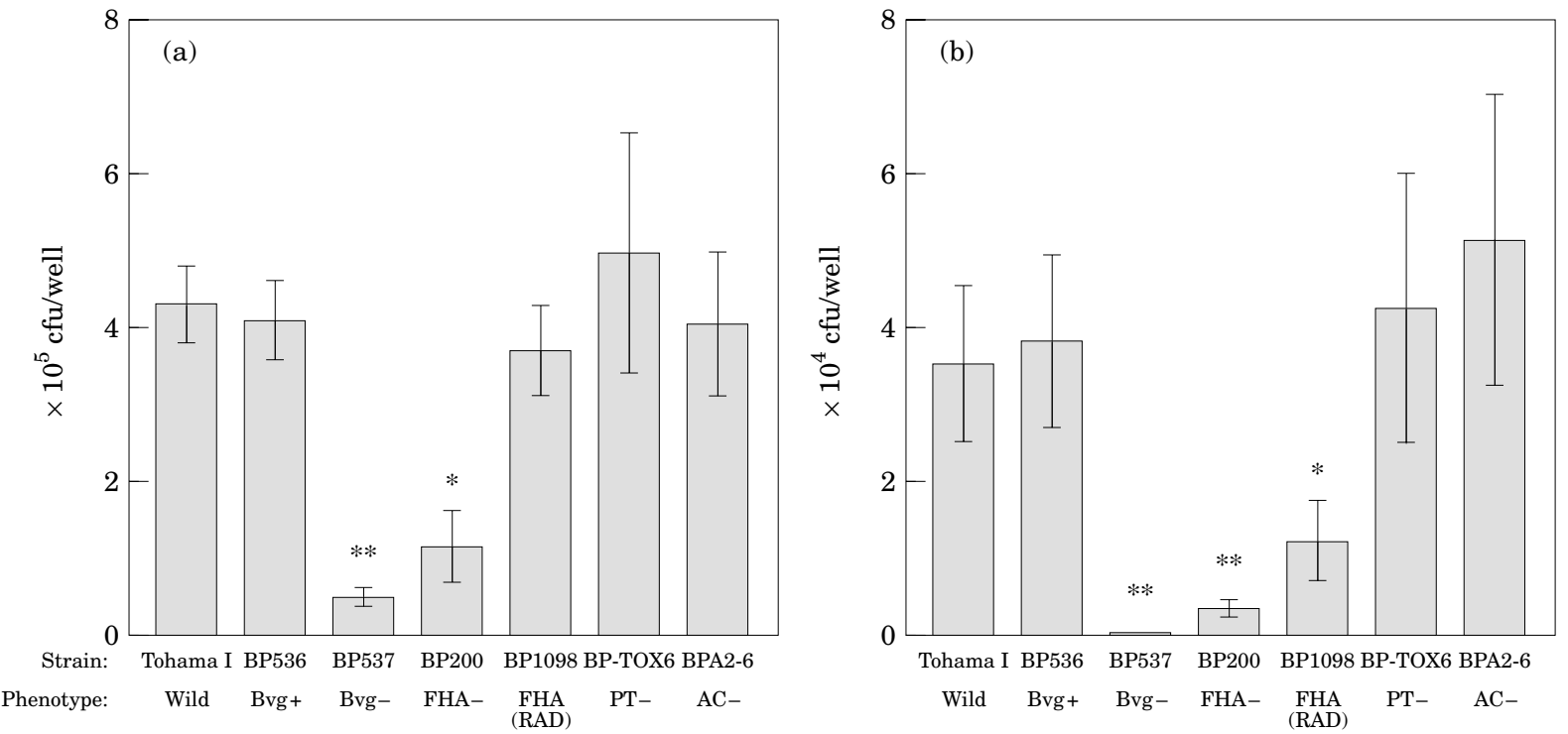

Figure 3. Adhesion and invasion profiles of strain BP536 and its isogenic derivatives for A549 cells. A549 cells $\left(1 \times 10^{5}\right.$ cells / well) were infected with $10^{7} \mathrm{cfu} B$. pertussis mutant strains at $37^{\circ} \mathrm{C}$ for $2 \mathrm{~h}$. The numbers of viable cell-associated bacteria (a) and intracellular bacteria (b) were determined. The values represent the means \pm SE of four experiments. ${ }^{*} P<0.05 ; * * P<0.01$ vs parental strain.
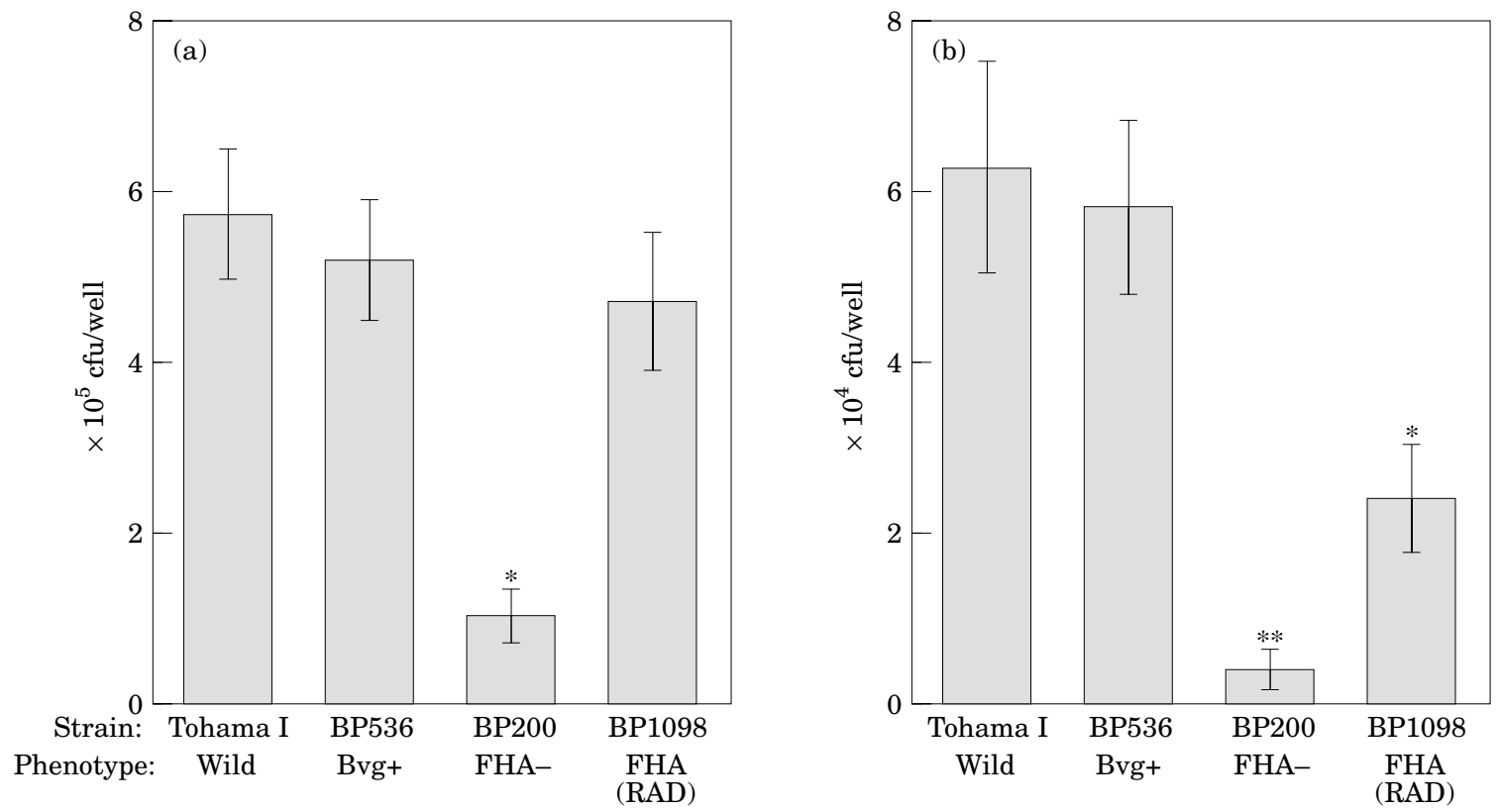

Figure 4. Adhesion and invasion profiles of strain BP536 and its isogenic derivatives for NHBE cells. NHBE cells $\left(1 \times 10^{5}\right.$ cells/well) were infected with $10^{7} \mathrm{cfu}$ B. pertussis at $37^{\circ} \mathrm{C}$ for $2 \mathrm{~h}$. The numbers of viable cellassociated bacteria (a) and intracellular bacteria (b) were determined. The values represent the means $\pm S E$ of four experiments. $* P<0.05 ; * * P<0.01$ vs parental strain.

the parental strain BP536. These results suggest that $B$. pertussis FHA plays a major role in the adherence to, and invasion of A549 cells, and that the 1097RGD1099 sequence of FHA may contribute to the invasion process.
Next, we used the normal human bronchial epithelial (NHBE) cells as a more relevant cell for testing the role of FHA in B. pertussis invasion. NHBE cells were infected with $B$. pertussis mutant strains at an moi of 100 , and bacterial ad- 
(a)

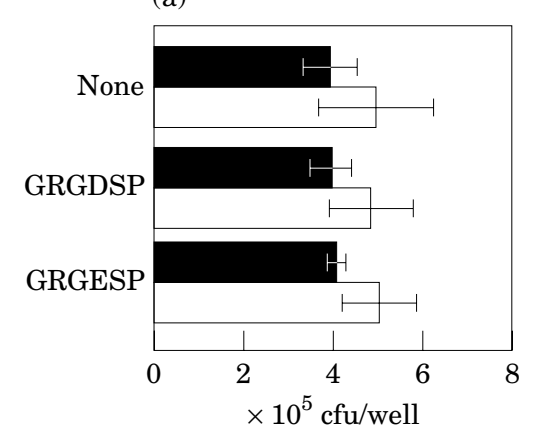

(b)

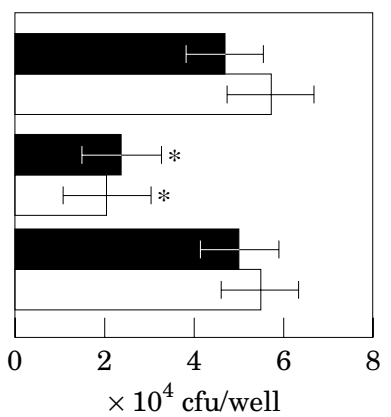

Figure 5. Effect of synthetic peptide on adherence and invasion of B. pertussis BP536 to A549 and NHBE cells. A549 ( $\square)$ and NHBE $(\square)$ cells $\left(1 \times 10^{5}\right.$ cells/well) were infected with $10^{7}$ cfu B. pertussis in the presence of $1.5 \mathrm{mM}$ synthetic peptides, and the numbers of viable cell-associated bacteria (a) and intracellular bacteria (b) were determined. The values represent the means \pm SE of five experiments. ${ }^{*} P<0.05$ vs control.

herence and invasion were determined after $2 \mathrm{~h}$ incubation (Fig. 4). The adhesive and invasive properties of strain BP536 were similar to those of wild type strain Tohama I. Strain BP200 (FHA-) adhered to NHBE cells at considerably lower levels than did strain BP536 (20.6\% of BP536; $P<0.05$ ). Strain BP1098 (FHA RAD) adhered equally well to NHBE cells as did BP536, but invaded less well (42.1\% of BP536; $P<0.05)$. There was no difference in adhesive and invasive properties of strain BP-TOX6 and strain A2-6 relative to strain BP536 (data not shown). These results were essentially identical to those obtained with A549 cells.

\section{RGD peptide inhibits invasion of human respiratory epithelial cells by $B$. pertussis}

To corroborate the involvement of the FHA RGD sequence in bacterial invasion, we examined the ability of an RGD-containing synthetic peptide to inhibit invasion by B. pertussis. A549 and NHBE cells were infected with strain BP536 in the presence or absence of synthetic GRGDSP peptide $(1.5 \mathrm{mM})$ for $2 \mathrm{~h}$ at $37^{\circ} \mathrm{C}$, and the numbers of cell-associated and intracellular bacteria were determined (Fig. 5). The invasion of A549 and NHBE cells by B. pertussis BP536 was significantly reduced to $50.0 \%(P<0.05)$ and $39.2 \%$ $(P<0.05)$ of control, respectively, in the presence of the GRGDSP peptide [Fig. 5(b)]. In contrast, no inhibition was observed when the non-active GRGESP peptide was present. Neither the GRGDSP or the GRGESP peptide influenced the adhesion process [Fig. 5(a)]. These results confirmed a role for the FHA RGD sequence in the invasion process.

\section{Human $\alpha 5 \beta 1$ integrin promote bacterial invasion of respiratory epithelial cells}

The RGD sequence motif represents one of the major cell-attachment domains of the extracellular matrix (ECM) proteins and is recognized by integrin receptors $[22,23]$. Integrins have also been found to mediate intracellular invasion by some microbial pathogens $[12,15]$. To examine if RGD-binding integrins are involved in B. pertussis invasion of respiratory epithelial cells, we assessed the ability of several anti-integrin monoclonal antibodies to inhibit invasion of A549 cells by B. pertussis BP536. A549 cells were preincubated with one of several monoclonal antibodies $(25 \mu \mathrm{g} / \mathrm{ml})$ for $30 \mathrm{~min}$ at $37^{\circ} \mathrm{C}$, and then infected with strain BP536 for $2 \mathrm{~h}$ (Fig. 6). Monoclonal antibodies directed against the integrin $\alpha 5$ and $\beta 1$ subunits were found to inhibit invasion of A549 cells by B. pertussis (29.1 and $29.7 \%$ of control; $P<0.05$, respectively). In contrast, monoclonal antibodies directed against integrin chains $\alpha \mathrm{V}, \alpha 2, \alpha 3, \alpha 6$ and $\beta 3$ had no inhibitory effect. None of anti-integrin monoclonal antibodies influenced adherence process (data not shown). We further tested the ability of a monoclonal antibody directed against an epitope found only in the $\alpha 5 \beta 1$ heterodimer (very late antigen-5; VLA-5) to inhibit invasion of A549 and NHBE cells (Fig. 6). This monoclonal antibody also inhibited invasion of both cell types by $B$. pertussis, suggesting that the $\alpha 5 \beta 1$ 

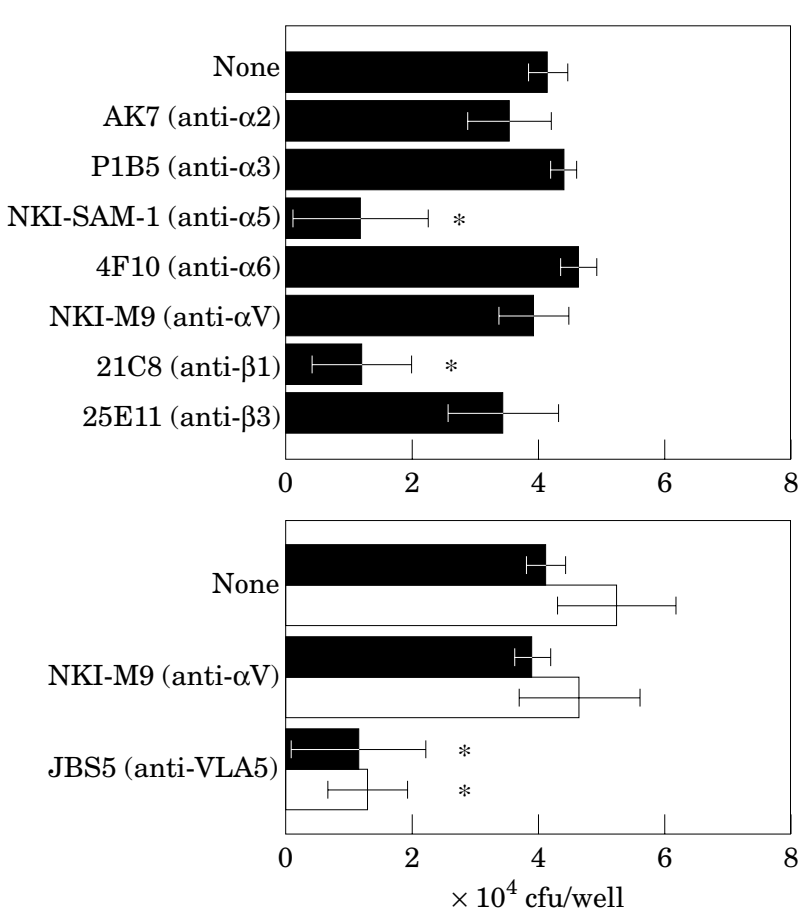

Figure 6. Effects of anti-integrin monoclonal antibodies on B. pertussis invasion. A549 monolayers were incubated with monoclonal antibodies recognizing the indicated integrin subunits for $30 \mathrm{~min}$ prior to addition of bacteria (upper panel). A549 and NHBE ( $\square$ ) monolayers were incubated with monoclonal antibodies directed against $\alpha \mathrm{V}$ integrin subunit or VLA-5 for $30 \mathrm{~min}$ prior to addition of bacteria (lower panel). Thereafter, the standard assay procedure was followed. The values represent the means \pm SE of four experiments. $* P<0.05$ vs control.

integrin may be required for bacterial invasion of human respiratory epithelial cells. Control experiments were performed to verify that the inhibitory monoclonal antibodies did not adversely affect bacterial and host cell viabilities (data not shown).

\section{Discussion}

There is increasing evidence that adults serve as the primary reservoir for $B$. pertussis and facilitate its spread to susceptible children [24, 25]. B. pertussis is capable of invading monocytes/macrophages and respiratory epithelial cells [7-9], although it does not appear to replicate to a significant degree inside these cells. The ability to enter host cells may lead to the establishment of an intracellular reservoir of viable $B$. pertussis. In the present study we investigated the mechanisms by which $B$. pertussis invade human respiratory epithelial cells. B. pertussis FHA appears to play a major role in adherence to, and invasion of, A549 and NHBE cells based upon the impaired activities of a FHA-deficient isogenic strain. This observation is consistent with a previous report describing a role for FHA in invasion of human tracheal epithelial cells [7]. Our study also demonstrated that the FHA RGD sequence at residues 10971099 is involved in invasion of human respiratory epithelial cells by $B$. pertussis, and that human $\alpha 5 \beta 1$ integrin may serve as a receptor for $B$. pertussis invasion. Several types of evidence favour the roles of the FHA RGD sequence and human $\alpha 5 \beta 1$ integrin in the invasion process: (1) a mutant strain, in which the FHA RGD motif had been changed to RAD, was much less invasive than the parental strain; and (2) both, a synthetic GRGDSP peptide and a monoclonal antibody directed against the $\alpha 5 \beta 1$ integrin were able to inhibit invasion of A549 and NHBE cells by B. pertussis.

Exploitation of $\alpha 5 \beta 1$ integrin by B. pertussis for the purposes of invasion is not a unique strategy among microbial pathogens. Yersinia pseudotuberculosis and $Y$. enterocolitica can bind to various $\beta 1$ integrins on several mammalian cells via the Inv protein, thereby promoting their ingestion [12]. Shigella flexneri can penetrate into mammalian cells through the interaction of IpaB, IpaC and IpaD proteins with $\alpha 5 \beta 1$ integrin [15]. Furthermore, Trypanosoma cruzi, Leishmania sp., Streptococcus pyogenes and various Mycobacteria species can bind fibronectin and interact with VLA-5 via this molecular bridge [26-31]. It is worth noting that some properties of the interaction of FHA with $\alpha 5 \beta 1$ integrin are apparently different from the characteristics reported for Yersinia Inv protein and Shigella flexineri Ipa protein. Inv protein interacts with $\beta 1$ integrins in a manner independent of RGD, and the Ipa protein- $\alpha 5 \beta 1$ integrin interaction is not inhibited by RGDS peptide $[12,15,32]$. In contrast, FHA/ $\alpha 5 \beta 1$ integrin-mediated $B$. pertussis invasion appears to be an RGD-dependent. It would be of great interest to distinguish further the functional consequences of the interaction of the FHA RGD with $\alpha 5 \beta 1$ integrin from those of Inv or Ipa protein at the molecular level. Interestingly, the FHA RAD mutant strain retained the ability to adhere to A549 and NHBE cells, although its invasiveness was significantly impaired. This observation was corroborated by 
the finding that the RGD-containing peptide had no effect on adherence of $B$. pertussis. These data suggest that the RGD sequence of FHA contributes to the invasion process rather than to the adhesion process; other portions of the FHA protein such as the carbohydrate recognition domain or heparin-binding domain may contribute to the adhesion process.

Menozzi et al. [21] have shown that the heparin-inhibitable binding activity of FHA is largely responsible for attachment of B. pertussis to epithelial cells. They have postulated that low-affinity ligands, like heparan sulfate, may help to attach the pathogen to the target cell, and a specific interaction with target cell proteins may then be required for internalization [21]. It is therefore possible that the heparin-binding domain of FHA provides the molecular basis of initial attachment of $B$. pertussis to the surface of human respiratory epithelial cells. This initial binding might then be followed by interaction of the RGD sequence of FHA with $\alpha 5 \beta 1$ integrin to mediate bacterial entry. This idea was supported by evidence that heparin $(100 \mu \mathrm{g} / \mathrm{ml})$ was able to inhibit adherence of the BP536 strain to A549 and NHBE cells by 18.2 and $20.4 \%$ of control, respectively (data not shown). The PTdeficient strain showed similar adhesive and invasive properties to those of the parental strain, consistent with a previous report that PT does not play a role in the invasion of epithelial cells by B. pertussis [7]. However, in contrast to an earlier report describing an inhibitory effect of AC on entry of B. pertussis into HTE and HeLa cells $[7,8]$, we found no evidence for a significant inhibitory effect of AC in the entry of $B$. pertussis into A549 cells. In our assay system, with the AC-deficient mutant strain as well as with the parental strain, the standard errors of the measurements could have masked an inhibitory effect of AC (Fig. 3). We did not address the roles of Prn and Fim in the invasion process. It is intriguing that Fim can interact with VLA-5 on monocytes, resulting in enhanced CR3 activity [33]. However, Bassinet et al. [7] have recently demonstrated that Fim is not involved in invasion of HTE cells by B. pertussis, and that Prn inhibits the invasion process.

It is unclear whether FHA-mediated B. pertussis invasion takes place in vivo. $\beta 1$ integrin expression is polarized to the basolateral membrane of epithelium in the respiratory airway $[34,35]$. Injury of the airway epithelium can occur during exposure to a variety of infectious agents such as Haemophilus influenzae and Pseudomonas aeruginosa, in addition to B. pertussis, leading to epithelial wound repair following the shedding of the surface epithelial cells [36-38]. Regenerating airway epithelial cells display enhanced expression and apical distribution of a5ß1 integrin [34, 35]. Roger et al. [35] have demonstrated that $P$. aeruginosa can adhere to the repairing airway epithelium through the interaction of a $50 \mathrm{kDa}$ outer membrane protein with apically distributed $\alpha 5 \beta 1$ integrin. B. pertussis is known to destroy the ciliated cells that line the respiratory tract [38]. Thus, the overexpression and apical distribution of $\alpha 5 \beta 1$ integrin on the respiratory epithelium during the repair process after injury could contribute to FHA RGD-mediated B. pertussis invasion. Injured or activated epithelial cells (during infection) may show various inflammatory responses, including secretion of chemokines, and expression of adhesion molecules [39, 40]. Studies are currently under way in our laboratory to examine the regulation of adhesion molecule expression as well as the cytokine production in response to B. pertussis invasion of respiratory epithelial cells.

In conclusion, the data from our study suggest that $B$. pertussis FHA may promote invasion of human respiratory epithelial cells through the interaction of its RGD sequence with host cell a5 $\beta 1$ integrin. The identification of a bacterial ligand and its host receptor involved in $B$. pertussis invasion provides an important insight into the understanding of $B$. pertussis pathogenesis.

\section{Materials and Methods}

\section{Bacterial strains and culture conditions}

Bacterial strains used in this study are listed in Table 1. Bacteria were cultured for 2 days on Bordet-Gengou (BG) agar plates (Difco Laboratories, Detroit, MI, U.S.A.) supplemented with $15 \%$ sheep blood. Before use, bacteria were harvested from the plates and suspended in Dulbecco's phosphate-buffered saline (PBS; $\mathrm{pH} 7.4$ ) to a concentration of $1 \times 10^{8}$ colony forming unit $(\mathrm{cfu}) / \mathrm{ml}$ as estimated by optical density at $600 \mathrm{~nm}$. Actual concentrations of viable bacteria were determined by colony counts after plating on $B G$ agar. 
Table 1. Strains of B. pertussis used in this study

\begin{tabular}{|c|c|c|}
\hline Strain & $\begin{array}{l}\text { Relevant phenotype or } \\
\text { genotype }\end{array}$ & Reference \\
\hline Tohama I & Virulent phase (wild type) & [41] \\
\hline BP536 & $\begin{array}{l}\text { Str }{ }^{R} \text { derivative of Tohama I } \\
(\mathrm{Bvg}+)\end{array}$ & [41] \\
\hline BP537 & $\begin{array}{l}\text { Contains frameshift } \\
\text { mutation in bvgS resulting } \\
\text { in avirulent-phase } \\
\text { phenotype (Bvg-) and } \\
\text { deficient expression of } \\
\text { multiple proteins including } \\
\text { FHA, AC and PT }\end{array}$ & [6], [41] \\
\hline BP200 & $\begin{array}{l}\text { Contains a complete } \\
\text { deletion of the FHA } \\
\text { structural gene, fhaB, } \\
\text { resulting in deficient } \\
\text { expression of FHA protein }\end{array}$ & [18] \\
\hline BP1098 & $\begin{array}{l}\text { Contains single amino acid } \\
\text { substitution in FHA } \\
\text { sequence RGD (1097-9): } \\
\text { G1098A (flaB1098) }\end{array}$ & [19] \\
\hline BP-ТOX6 & $\begin{array}{l}\text { Contains deletion of PT } \\
\text { operon }(p t x \Delta 6)\end{array}$ & [19] \\
\hline BPA2-6 & $\begin{array}{l}\text { Contains amino acid } \\
\text { substitution in CyaA AC } \\
\text { catalytic site }(\mathrm{K} 58 \mathrm{M}) \\
\text { resulting in loss of } \\
\text { enzymatic activity }\end{array}$ & {$[42]$} \\
\hline
\end{tabular}

\section{Monoclonal antibodies and peptides}

The following monoclonal antibodies against human cell surface proteins were used: AK7 (anti-integrin $\alpha 2$, IgG1; CD49b), P1B5 (antiintegrin a3, IgG1; CD49c), NKI-SAM-1 (antiintegrin $\alpha 5$, IgG2b; CD49e), 4F10 (anti-integrin a6, IgG2b; CD49f), NKI-M9 (anti-integrin $\alpha \mathrm{V}$, IgG1; CD51), 21C8 (anti-integrin $\beta 1, \quad$ IgG1; CD29), 25E11 (anti-integrin $\beta 3$, IgG2a; CD61) and JBS5 (anti-integrin $\alpha 5 \beta 1$, IgG; VLA-5) (Chemicon International Inc., Temecula, CA, U.S.A.). The six-amino-acid peptides GRGDSP and GRGESP were purchased from Takara Biochemicals (Otsu, Japan). Lyophilized peptides were dissolved in RPMI1640 medium and filter sterilized; aliquots were stored at $-80^{\circ} \mathrm{C}$.

\section{Eukaryotic cells and their cultivation}

The human lung epithelial cell line A549 was obtained from Riken Cell Bank, Japan
(RCB0098), and normal human bronchial epithelial (NHBE) cells from BioWhittaker, Inc. (Walkersville, MD, U.S.A.). A549 cells were cultured in RPMI1640 medium (Nissui Co., Japan) supplemented with $2 \mathrm{mM}$ L-glutamine, $10 \%$ heat-inactivated fetal bovine serum (FBS), $100 \mathrm{U}$ of sodium penicillin $\mathrm{G} / \mathrm{ml}$, and $100 \mu \mathrm{g}$ of streptomycin $/ \mathrm{ml}$. NHBE cells were grown in bronchial epithelial growth medium (BEGM; BioWhittaker, Inc.). BEGM consists of bronchial epithelial basal medium (BEBM) supplemented with recombinant human epidermal growth factor (rhEGF), insulin, hydrocortisone, transferrin, tri-iodothyronine, epinephrine, pituitary extract $(\mathrm{PE})$ and retinoic acid. Cells were maintained at $37^{\circ} \mathrm{C}$ in a humidified atomosphere containing $5 \% \mathrm{CO}_{2}$.

\section{Bacterial adherence and invasion assays}

For adherence and invasion assays, $1 \times 10^{5}$ cells / well were seeded into 24 well tissue culture plates $18 \mathrm{~h}$ before the assays. The epithelial cell monolayers in 24 well tissue culture plates were washed three times and incubated with unsupplemented medium for $2 \mathrm{~h}$ prior to bacterial challenge. The epithelial cell monolayers were infected with $1 \times 10^{7}$ bacterial cfu and incubated at $37^{\circ} \mathrm{C}$ in $5 \% \mathrm{CO}_{2}$ for $2 \mathrm{~h}$, unless otherwise noted. To determine the number of cell-associated bacteria, infected monolayers were washed three times with PBS to remove nonassociated bacteria, lysed by adding $200 \mu$ l of a saponin (Sigma) solution $(1 \mu \mathrm{g} / \mathrm{ml}$ in PBS) for $15 \mathrm{~min}$ at $37^{\circ} \mathrm{C}$. After repeated pipetting and vortexing, the suspension was plated out in serial dilutions on BG agar to determine the number of cfu. To quantitate bacterial invasion, a gentamicin-based protection method was performed $[3,8]$. The epithelial cell monolayers infected with bacteria at a multiplicity of infection (moi) of 100 for $2 \mathrm{~h}$ were washed three times and further incubated with the appropriate medium containing $100 \mu \mathrm{g}$ gentamicin $/ \mathrm{ml}$ for $2 \mathrm{~h}$ to kill extracellular bacteria. In separate experiments, $B$. pertussis strains suspended at a density equivalent to that used in invasion assays were treated by incubation with $100 \mu \mathrm{g}$ gentamicin $/ \mathrm{ml}$ for $2 \mathrm{~h}$ in the absence of epithelial cells. This procedure reduced the number of viable bacteria from $1 \times 10^{7}-20 \mathrm{cfu}$, indicating that gentamicin efficiently killed extracellular bacteria. After washing three times with PBS, intracellular bacteria were released by saponin 
treatment and the number of cfu was determined as described above. All samples were assayed in triplicate, and each assay was repeated at least four times. The statistical significance of data was determined by the Students $t$-test. $P$ values of $<0.05$ were considered significant.

\section{Transmission electron microscopy (TEM)}

The epithelial cell monolayers were infected with bacteria at an moi of 100 at $37^{\circ} \mathrm{C}$ for $2 \mathrm{~h}$. The infected cell monolayers were fixed with $2 \%$ glutaraldehyde, post fixed with $1 \%$ osmium tetroxide, dehydrated, infiltrated and embedded in epoxy resin for sections. Thin sections of the cells were contrasted with uranyl acetate and lead citrate, and observed under a Hitachi HU12A electron microscope.

\section{Acknowledgements}

This work was supported in part by a grant from Meiji Pharmaceutical University to Y.I. and by a grant from NIH (R01 AI39587) to D.A.R.

\section{References}

1 Friedman RL. Pertussis: the disease and new diagnostic methods. Clin Microbiol Rev 1988; 1: 365-76.

2 Relman DA. Bordetella pertussis: determinants of virulence. In: Moss J, Iglewski B, Vaughan M, Tu AT, Eds. Handbook of Natural Toxins. New York: Marcel Dekker, 1995: 367405.

3 Weiss AA, Hewlett EL. Virulence factor of Bordetella pertussis. Annu Rev Microbiol 1986; 40: 661-86.

4 Arico B, Miller JF, Roy C et al., Sequences required for expression of Bordetella pertussis virulence factors share homology with prokaryotic signal transduction proteins. Proc Natl Acad Sci USA 1989; 86: 6671-5.

5 Roy CR, Miller JF, Falkow S. The bvgA gene of Bordetella pertussis encodes a transcriptional activator required for coordinate regulation of several virulence genes. $J$ Bacteriol 1989; 171: 6338-44.

6 Stibitz S, Aaronson W, Monack D, Falkow S. Phase variation in Bordetella pertussis by frameshift mutation in a gene for a novel two-component system. Nature 1989; 338: 266-9.

7 Bassinet L, Gueirard P, Maitre B, Housset B, Gounon $P$, Guiso N. Role of adhesins and toxins in invasion of human tracheal epithelial cells by Bordetella pertussis. Infect Immun 2000; 68: 1934-41.

8 Ewanowich CA, Melton AR, Weiss AA, Sherburne RK, Peppler MS. Invasion of HeLa 229 cells by virulent Bordetella pertussis. Infect Immun 1989; 57: 2698-704.
9 Friedman RL, Nordensson K, Wilson L, Akporiaye ET, Yocum DE. Uptake and intracellular survival of Bordetella pertussis in human macrophages. Infect Immun 1992; 60: 4578-85.

10 Hellwig SMM, Hazenbos WLW, Van de Winkel JGJ, Mooi FR. Evidence for an intracellular niche for Bordetella pertussis in broncho-alveolar lavage cells of mice. FEMS Immunol Med Microbiol 1999; 26: 203-7.

11 Lee CK, Roberts AL, Finn TM, Knapp S, Mekalanos JJ. A new assay for invasion of HeLa 229 cells by Bordetella pertussis: effect of inhibitors, phenotypic modulation, and genetic alterations. Infect Immun 1990; 58: 2516-22.

12 Isberg RR, Leong JM. Multiple $\beta 1$ chain integrins are receptors for invasin, a protein that promotes bacterial penetration into mammalian cells. Cell 1990; 60: 861-71.

13 Lecuit M, Dramsi S, Gottardi C, Fedor-Chaiken M, Gumbiner B, Cossart P. A single amino acid in Ecadherin responsible for host specificity towards the human pathogen Listeria monocytogenes. EMBO J 1999; 18: 3956-63.

14 Mengaud J, Ohayon H, Gounon P, Mege RM, Cossart $\mathrm{P}$. E-cadherin is the receptor for internalin, a surface protein required for entry of L. monocytogenes into epithelial cells. Cell 1996; 84: 923-32.

15 Watarai M, Funato S, Sasakawa C. Interaction of Ipa proteins of Shigella flexneri with $\alpha 5 \beta 1$ integrin promotes entry of the bacteria into mammalian cells. J Exp Med 1996; 183: 991-9.

16 Roberts MN, Fairweather F, Leininger E, et al. Construction and characterization of Bordetella pertussis mutants lacking the vir-regulated P.69 outer membrane protein. Mol Microbiol 1991; 5: 1393-404.

17 Renauld-Mongenie G, Cornette J, Mielcarek N, Menozzi FD, Locht C. Distinct roles of the N-terminal and Cterminal precursor domains in the biogenesis of the Bordetella pertussis filamentous hemagglutinin. J Bacteriol 1996; 178: 1053-60.

18 Ishibashi Y, Claus S, Relman DA. Bordetella pertussis filamentous hemagglutinin interacts with a leukocyte signal transduction complex and stimulates bacterial adherence to monocyte CR3 (CD11b/CD18). J Exp Med 1994; 180: 1225-33.

19 Relman D, Tuomanen E, Falkow S, Golenbock DT, Saukkonen K, Wright SD. Recognition of a bacterial adhesion by an integrin: macrophage CR3 ( $\alpha \mathrm{M} \beta 2$, $\mathrm{CD} 11 \mathrm{~b} / \mathrm{CD} 18$ ) binds filamentous hemagglutinin of Bordetella pertussis. Cell 1990; 61: 1375-82.

20 Prasad SM, Yin Y, Rodzinski E, Tuomanen EI, Masure HR. Identification of a carbohydrate recognition domain in filamentous hemagglutinin from Bordetella pertussis. Infect Immun 1993; 61: 2780-5.

21 Menozzi FD, Mutombo R, Renauld G, et al. Heparininhabitable lectin activity of the filamentous hemagglutinin adhesin of Bordetella pertussis. Infect Immun 1994; 62: 769-78.

22 Mette SA, Pilewski J, Buck CA, Albelda SM. Distribution of integrin cell adhesion receptors on normal bronchial epithelial cells and lung cancer cells in vitro and in vivo. Am J Respir Cell Mol Biol 1993; 8: 562-72.

23 Ruoslahti E, Pierschbacher MD. New perspectives in cell adhesion: RGD and integrins. Science 1987; 238: 491-7.

24 Biellik RJ, Patriarca PA, Mullen JR, et al. Risk factors for community- and household-aquired pertussis during a large-scale outbreak in central Wisconsin. J Infect Dis 1988; 157: 1134-41. 
25 Nelson JD. The changing epidemiology of pertussis in young infants: the role of adults as reservoirs of infection. Am J Dis Child 1978; 132: 371-3.

26 Cue D, Southern SO, Southern PJ, et al. A nonpeptide integrin antagonist can inhibit epithelial cell ingestion of Streptococcus pyogenes by blocking formation of integrin $\alpha 5 \beta 1$-fibronectin-M1 protein complexes. Proc Natl Acad Sci USA 2000; 97: 2858-63.

27 Thole JER, Schdningh R, Janson AAM, et al. Molecular and immunological analysis of a fibronectin-binding protein antigen secreted by Mycobacterium leprae. Mol Microbiol 1992; 6: 153-63.

28 Wirth JJ, Kierzenbaum F. Fibronectin enhances macrophage association with invasive forms of Trypanosoma cruzi. J Immunol 1984; 133: 460-4.

29 Wyler DJ, Sypek JP, McDonald JA. In vitro parasitemonocyte interactions in human leishmaniasis: possible role of fibronectin in parasite attachment. Infect Immun 1985; 49: 305-11.

30 Young VB, Falkow S, Schoolnik GK. The invasin protein of Yersinia enterocolitica: internalization of invasin-bearing bacteria by eukaryotic cells is associated with reorganization of the cytoskeleton. J Cell Biol 1992; 166: 197-207.

31 Ouaissi MA, Afchain D, Capron A, Grimaud JA. Fibronectin receptors on Trypanosoma cruzi trypomastigotes and their biological function. Nature 1984; 308: 380-2.

32 Hamburger ZA, Brown MS, Isberg RR, Bjorkman PJ. Crystal structure of invasin: a bacterial integrin-binding protein. Science 1999; 286: 291-5.

33 Hazenbos WL, Van den Berg BM, Geuijen CW, Mooi FR, Van Furth R. Binding of FimD on Bordetella pertussis to very late antigen- 5 on monocytes activates complement receptor type 3 via protein tyrosine kinases. $J$ Immunol 1995; 155: 3972-8.
34 Pilewski JM, Latoche JD, Arcasoy SM, Albelda SM. Expression of integrin cell adhesion receptors during human airway epithelial repair in vivo. Am J Physiol (Lung Cell Mol Physiol) 1997; 273: L256-63.

35 Roger $\mathrm{P}$, Puchelle E, Bajolet-Laudinat $\mathrm{O}$, et al. Fibronectin and a5 $\beta 1$ integrin mediate binding of Pseudomonas aeruginosa to repairing airway epithelium. Eur Respir J 1999; 13: 1301-9.

36 Jackson AD, Cole P, Wilson R. Comparison of Haemophilus influenzae type $\mathrm{b}$ interaction with respiratory mucosa organ cultures maintained with an air interface or immersed xyledium. Infect Immun 1996; 64: 2353-5.

37 Tsang KWT, Rutman A, Tanaka E et al. Interaction of Pseudomonas aeruginosa with human respiratory mucosa in vitro. Eur Respir J 1994; 7: 1746-53.

38 Strauss E. New clues to whooping cough pathology. Science 1999; 285: 811-13.

39 DiMango E, Zar HJ, Bryan R, Prince A. Diverse Pseudomonas aeruginosa gene products stimulate respiratory epithelial cells to produce interleukin-8. J Clin Invest 1995; 96: 2204-10.

40 Frick AG, Joseph TD, Pang L, Rabe AM, St Geme JW, Look DC. Haemophilus influenzae stimulates ICAM-1 expression on respiratory epithelial cells. I Immunol 2000; 164: 4185-96.

41 Relman DA, Domenighini M, Tuomanen E, Rappuoli R, Falkow S. Filamentous hemagglutinin of Bordetella pertussis: nucleotide sequence and crucial role in adherence. Proc Natl Acad Sci USA 1989; 86: 2637-41.

42 Gross MK, Au DC, Smith AL, Storm DR. Targeted mutations that ablate either the adenylate cyclase or hemolysin function of the bifunctional cyaA toxin of Bordetella pertussis abolish virulence. Proc Natl Acad Sci USA 1992; 89: 4898-902. 